Diabetologia 9, 255-263 (1973)

(C) by Springer-Verlag 1973

\title{
The Glomerular Basement Membrane of the Rabbit Kidney on Long-Term Treatment with Heterologous Insulin Preparations of Different Purity*
}

\author{
H. Wehner, H. Huber and K.H. Kronenberg \\ Institute of Pathology, University of Tübingen,FRG \\ Received: November 6, 1972, accepted: April 2, 1973
}

Summary. A total of 90 rabbits were treated with monocomponent insulin (MC Actrapid Novo) and $\mathrm{a}+\mathrm{b}$ component (proinsulin, intermediates, "dimer", highmolecular proteins) and their solvents for 3 months without Freund's adjuvant. The insulin-binding eapacity of the serum, as an expression of the antibody titre, as well as the light and electron microscopic structure of the glomerular basement membrane were studied. It was shown that on treatment with MC insulin there was no significant antibody formation and no increased occurrence of subepithelial, hump-like, basement membrane protuberances. In contrast, following immunization with a + b component there was a significantly higher antibody titre and a pronounced increase in nodular basement membrane changes of the glomeruli. The findings show that the impurities ( $a+b$ component) in the insulins in normal commercial usage are evidently responsible for the higher antigenicity. Further, it can be demonstrated that investigations of glomerular structures allow one to draw conclusions as to the degree of the antigenicity of different insulin preparations although the actual cause of the increased occurrence of basement membrane changes with increasing antigenicity of the insulin preparation is still unclarified. Possible causes which ought to be discussed are deposition of immune complexes and/or increased and structurally atypical basement membrane synthesis.

Key words: Monocomponent insulin, proinsulin, insulin-antigenicity, glomerulus, glomerular basement membrane.
The insulin in normal commercial usage contains high-molecular ("a-component", "b-component", [proinsulin, intermediates, dimer etc.]) and low-molecular impurities (desamido-insulin, arginine-insulin ete.) which endow commercially available insulin preparations with a marked antigenicity and which result in the formation of antibodies (Fankhauser, 1969; Schlichtkrull, 1970). Due to purification of the recrystallized insulin with various techniques such as gel filtration on Sephadex G 50 and subsequent ion exchange chromatography of the low-molecular fraction (arginine-insulin), insulin and desamido-insulin a so-called monocomponent insulin (MC) has been prepared which is free from impurities (Sehlichtkrull, $1970,1971 \mathrm{a}, \mathrm{b}$ ). On injection in rabbits no antibodies are produced (Schlichtkrull, 1970).

We have demonstrated the existence of subepithelial protuberances on the glomerular basement membrane of the guinea pig whose prevalence is consistent with the insulin-binding capacity of the serum of insulin-immunized animals (Wehner and associates 1969).

The purpose of the present study was to investigate to what extent insulin antibodies or immunologically active insulin preparations play a rôle in the occurrence of changes of the glomerular basement membrane and whether quantitative correlations exist between the degree of the antigenicity of insulin preparations and the prevalence of the histological changes.

* Supported by the Deutsche Forschungsgemeinschaft (We $468 / 5$ )

\section{Material and Methods}

\section{Insulin Preparations and Solvents}

The following insulin preparations and solvents were employed for the experiments:

1. MC Actrapid (MC insulin Novo) (batch No. 4 and 9). This is a monocomponent insulin from porcine pancreas in neutral solution. It has a molecular weight of 6,000 . The solution has an insulin concentration of $40 \mathrm{units} / \mathrm{ml}$.

2. Solvent for the MC insulin (batch No. 3070).

This consists of a neutral solution of $7 \mathrm{mg}$ of sodium chloride, $1.4 \mathrm{mg}$ of sodium acetate $\left(3 \mathrm{H}_{2} \mathrm{O}\right)$ and $1 \mathrm{mg}$ of methyl p-oxybenzoate in $1 \mathrm{ml}$ of distilled water.

3. a + b component (bateh No. 471).

This substance is obtained from erystalline beef insulin being a mixture of the so-called a and b components, i.e. partial fractions, which are obtained on purification of the insulin. The a-component consists of high-molecular proteins, and the b-component of proinsulin, intermediates and "dimer". The biological insulin activity of the solution in the experimental animal is equivalent to $6-8$ units $/ \mathrm{ml}$; this can be explained by the fact that the structure of the insulin is present in part of the proteins (Schlichtkrull, personal communication). The molecular weight is higher than 8000 .

Solvent for $a+b$ component.

This is an acid solution ( $\mathrm{pH} 2.9$ ) of $0.04 \mathrm{mg}$ of zinc chloride, $50 \mathrm{mg}$ of glucose and $1 \mathrm{mg}$ of methyl p-oxybenzoate in $1 \mathrm{ml}$ of distilled water.

Experimental Animals, Controls and Mode of Treatment

The experiments were carried out in a total of 140 fullgrown rabbits (Belgian Giants, Piebalds) which were allocated as follows:

1. Fifty animals remained untreated for 3 months as normal controls.

2. Groups each of 30 animals received 20 units MC insulin or $0.8 \mathrm{mg} \mathrm{a}+\mathrm{b}$ component three times weekly subcutaneously in the cervical region over periods of up 
to 3 months and in isolated eases of up to 10 months. The treatment with the two insulin preparations was carried out without Freund's adjuvant. Between five and ten animals of each group were sacrificed at intervals of 1,2 and 3 months.

3. Twenty rabbits received $0.5 \mathrm{ml}$ of the solvent used for the MC insulin three times weekly over a period of up to three months. Five animals were sacrificed after 1 month, 10 animals after 2 months and 5 animals after 3 months.

4. Ten animals were treated in the same manner with $0.5 \mathrm{ml}$ of the solvent used for the $\mathrm{a}+\mathrm{b}$ component three times weekly. Five animals were sacrificed after 1 month and five animals after 3 months.

All animals received a 5 per cent glucose solution to drink which served the purpose of avoiding hypogly caemic reactions in the animals treated with insulin and $\mathrm{a}+\mathrm{b}$ component.

\section{Antibody Determination}

The insulin antibody titre (insulin-binding capacity (IBC) of the serum) was determined with $\mathrm{I}^{125}$ insulin and agar gel electrophoresis whereby the binding capacity in $\mu \mathrm{g} / \mathrm{ml}$ serum was calculated from the radioactivity in the fractions (Kallee and associates, 1963; Wehner and associates, 1972). We performed the determinations of the IBC $4,6,8,12,28,32$ and 40 weeks after commencement of immunization with MC insulin and $2,4,6,8,18,24$ and 28 weeks after commencement of treatment with $a+b$ component. The IBC was determined in the animals treated with the solvent 4,8 , and 12 weeks after commencement of the study.

\section{Histological Technique}

The kidneys were excised in each case in 5-10 animals at intervals of 4,8 , and 12 weeks, and in 2 additional cases (MC) after $7-10$ months. They were fixed in $4 \%$ buffered formalin solution (phosphate buffer $\mathrm{pH}$ 7) and fixed again for $2 \mathrm{~h}$ in osmic acid. After embedding in plexiglass, sections $0.5-1 \mu$ thick were prepared using an ultramicrotome and stained with silver impregnation after Movat (Wehner, 1970). We studied 50-100 different glomeruli on these sections per animal and in doing so we paid particular attention to small, brownish black, hump-like, subepithelial basement membrane protuberances which we have previously described in guinea pigs after insulin immunization (Wehner and associates, 1969). A glomerulus was assessed as changed if such protuberances were found on at least one site of the basement membrane. These quantitative investigations were made partly in a blind study.

After $1,2,3,7$ and 10 months small parts of the kidneys from 17 animals (Normal-2, MC $-5, a+b-10$ ) were fixed in $2 \%$ cacodylate-buffered glutaraldehyde solution for $4-6 \mathrm{~h}$ at $4^{\circ} \mathrm{C}$ for the electron microscopic studies immediately after removal (Sabatini and associates, 1962). Following washing in cacodylate buffer and $2 \mathrm{~h}$ subsequent contrasting in $1 \%$ buffered osmic acid they were embedded in araldite.

\section{Statistical Analysis}

We employed Student's t-test for the statistical evaluation of the main results. The limiting value for the confidence interval was $\alpha=0.05$.

\section{Results}

\section{Basement Membrane Changes}

The alterations of the basement membrane which we have already described (Wehner and associates,
1969) and which were observed after insulin immunization by light microscopy in the silver impregnation, were brownish black subepithelial structures which. appeared to be in continuous contact with the basement membrane. They could not be demarcated from the latter by current staining methods. These humplike protuberances can be observed either singly or in groups in the region of the peripheral basement membrane as well as in regions of the mesangial basement membrane. They are nodular, cone-like, spike-like or mushroom-like in shape (Fig. 1). Irregularly shaped fragments of these structures are to be found apparently inside the epithelial cell cytoplasm (Fig. 2), they also appear to lie partly outside. In one glomerulus we found changes which reminded one of an incipient perimembraneous glomerulonephritis.

Using electron microscopy it is apparent that these hump-like protuberances have the same electron density as the lamina densa. Their periphery is limited continuously by the lamina rara. The adjacent footprocesses of the epithelial cells are partly plump in these regions and are partly fused. The endothelium regularly covers the inside of the basement membrane which incidentally appears to be unchanged in most regions (Fig. 3). Other protuberances are bizarre and completely irregular in shape, occasionally in otherwise completely homogeneous structures bright spots are to be found. Further, it is evident that fragments of basement membrane protuberances lie between footprocesses in completely irregular arrangement or are surrounded by the foot-processes (Fig. 4). In such cases the foot-processes are partly delicate, partly plump and fused. A rare phenomenon is a peculiar splitting of the basement membrane in which evidently two lamina densae have developed and which could indicate a second newly formed basement membrane (Fig. 5).

\section{Prevalence of the Subepithelial Basement Membrane Protuberances}

Of a total of 50 untreated control animals only $1.1 \%$ on average of the glomeruli were changed. From the animals which had received MC insulin for 4 weeks $2.2 \%$ of the glomeruli showed the alterations described whereas at this point of time none of the glomeruli studied from the animals treated with the solvent showed any change. After 8 weeks of treatment with $\mathrm{MC}$ insulin we found basement membrane lesions in $5.3 \%$ of the glomeruli studied; the incidence was $6.4 \%$ in mean in the solvent-treated group $(\alpha<0.9)$. After 12 weeks' treatment with MC insulin $1.9 \%$ glomeruli showed similar changes, whereas the incidence was $4.7 \%$ in the solvent-treated controls $(\alpha<$ 0.1 ). The findings reported here evidently lie within the range of a certain biological deviation so that it does not appear that any statistically difference exists (Table 1).

In contrast, after four weeks' immunization $39.9 \%$ of the glomeruli studied from the animals treated with 
$a+b$ component were changed whereas the incidence was $12.8 \%$ in the solvent-treated animals $(\alpha<0.001)$. After eight weeks $27.2 \%$ of the glomeruli showed these was $14.1 \%$. Of the glomeruli from the control animals treated with the solvent $5.2 \%$ showed these changes at this point of time $(\alpha<0.001)$. The differences between

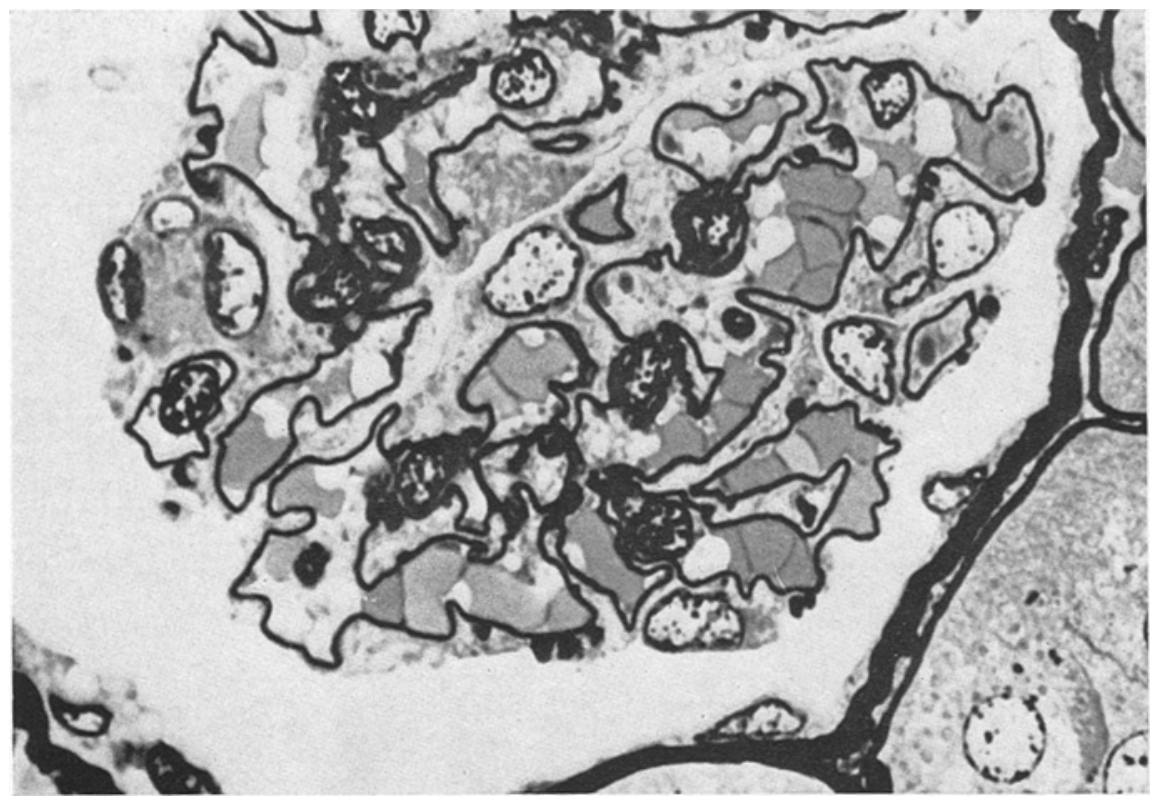

Fig. 1. Subepithelial, partly nodulax, partly cone-shaped basement membrane protuberances in a rabbit treated for 7 months, with $a$ and $b$ component. Silverimpregnation after Movat. Semithin section. 1320:1

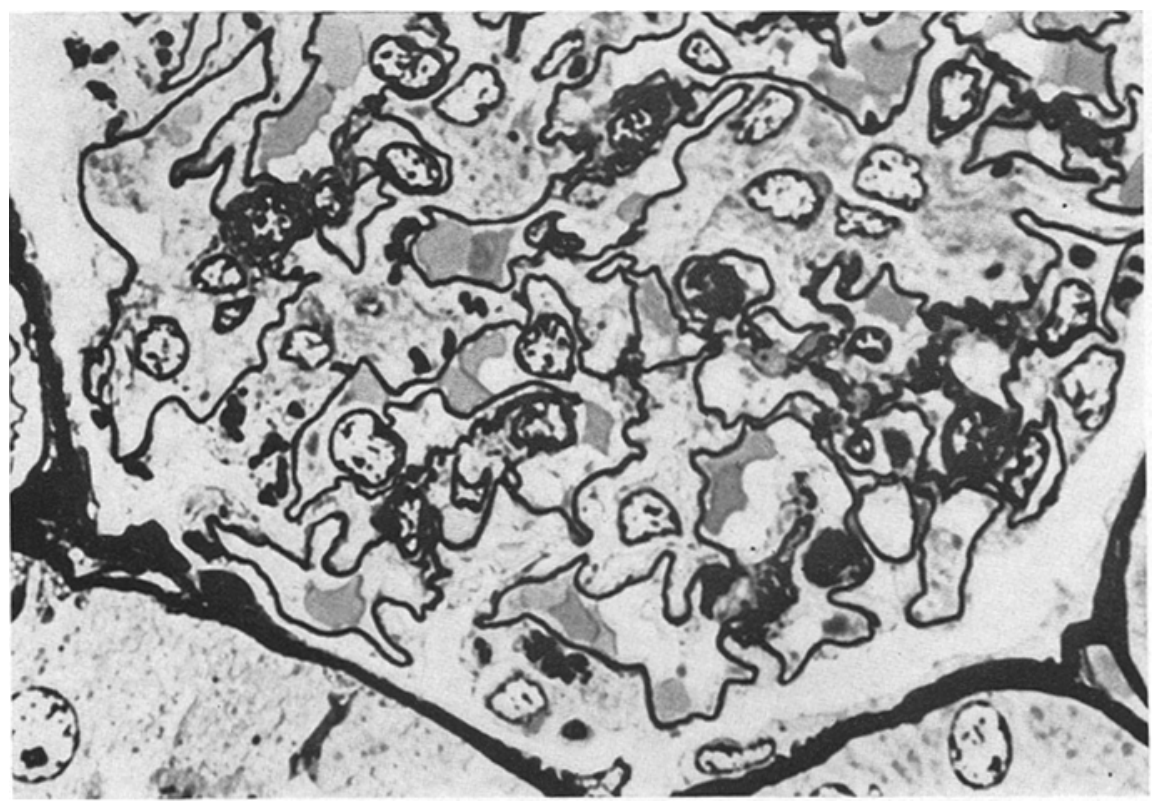

Fig. 2. Fragments of hump-like protuberanees inside epitholial cell cytoplasm. Rabbit, treated for 3 months with $a$ and $b$ component. Silverimpregnation after Movat. Semithin section 1320:1

changes (findings in solvent-treated controls are not available for this point of time) and after 12 weeks" immunization with $\mathrm{a}+\mathrm{b}$ component the incidence the $a+b$ component group and the MC and solvent groups are statistically significant (Table 1). 


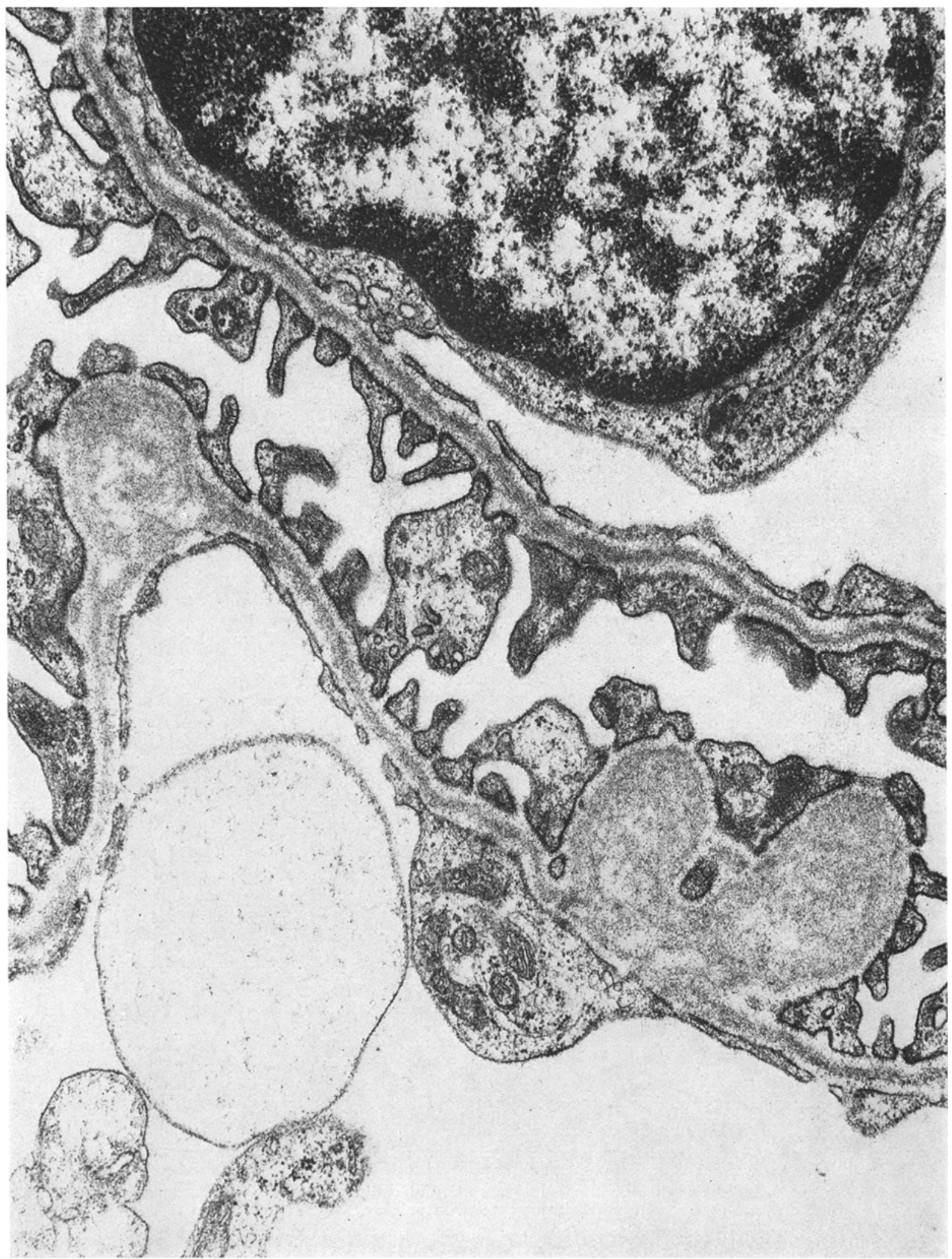

Fig. 3. Hump-like basement membrane protuberances Rabbit, treated for 2 months with a and b component $38700: 1$ 


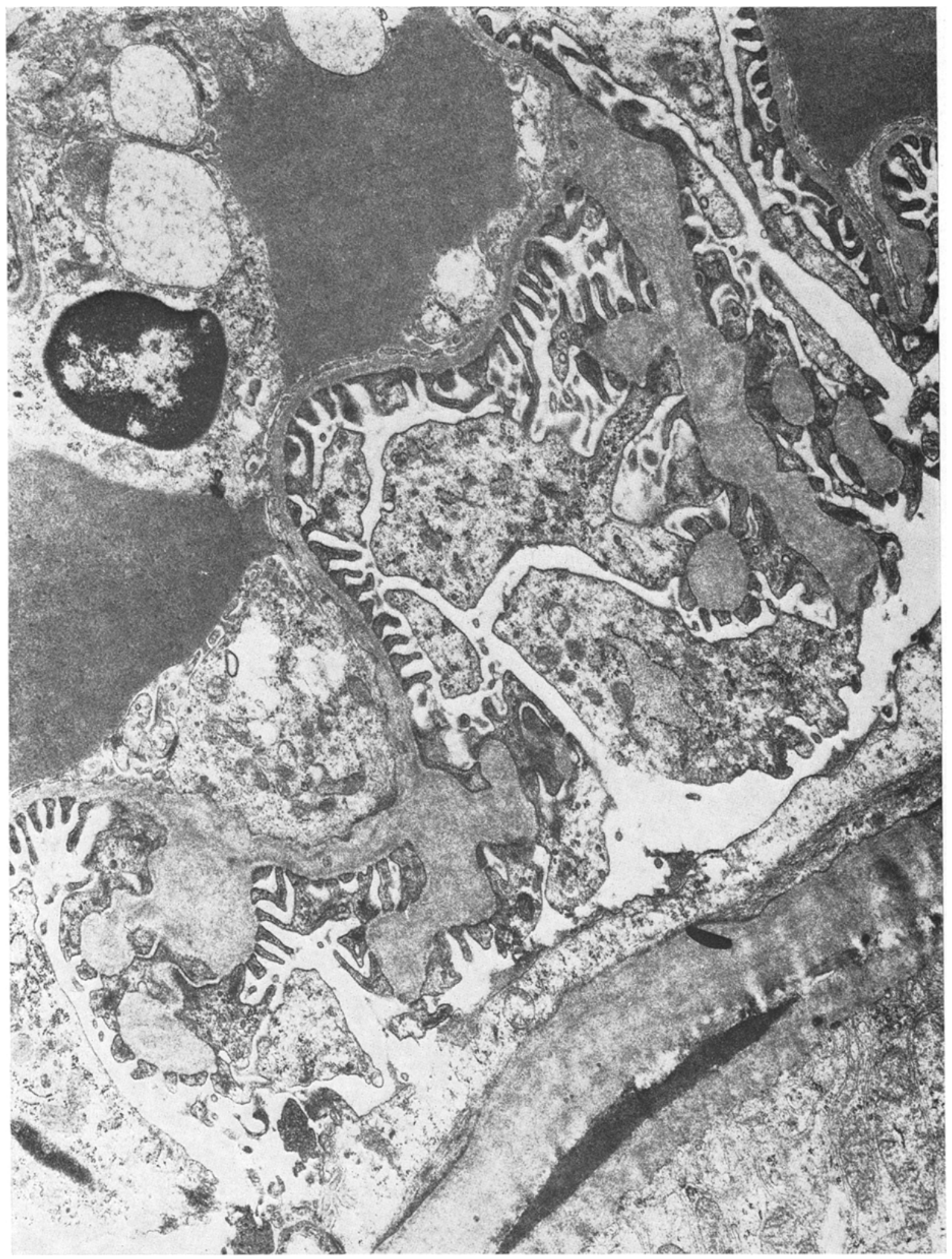

Fig. 4. Bizarre shaped basement membrane protuberances partly surrounded by foot processes. Rabbit, treated for 7 months with a and b component $21000: 1$ 


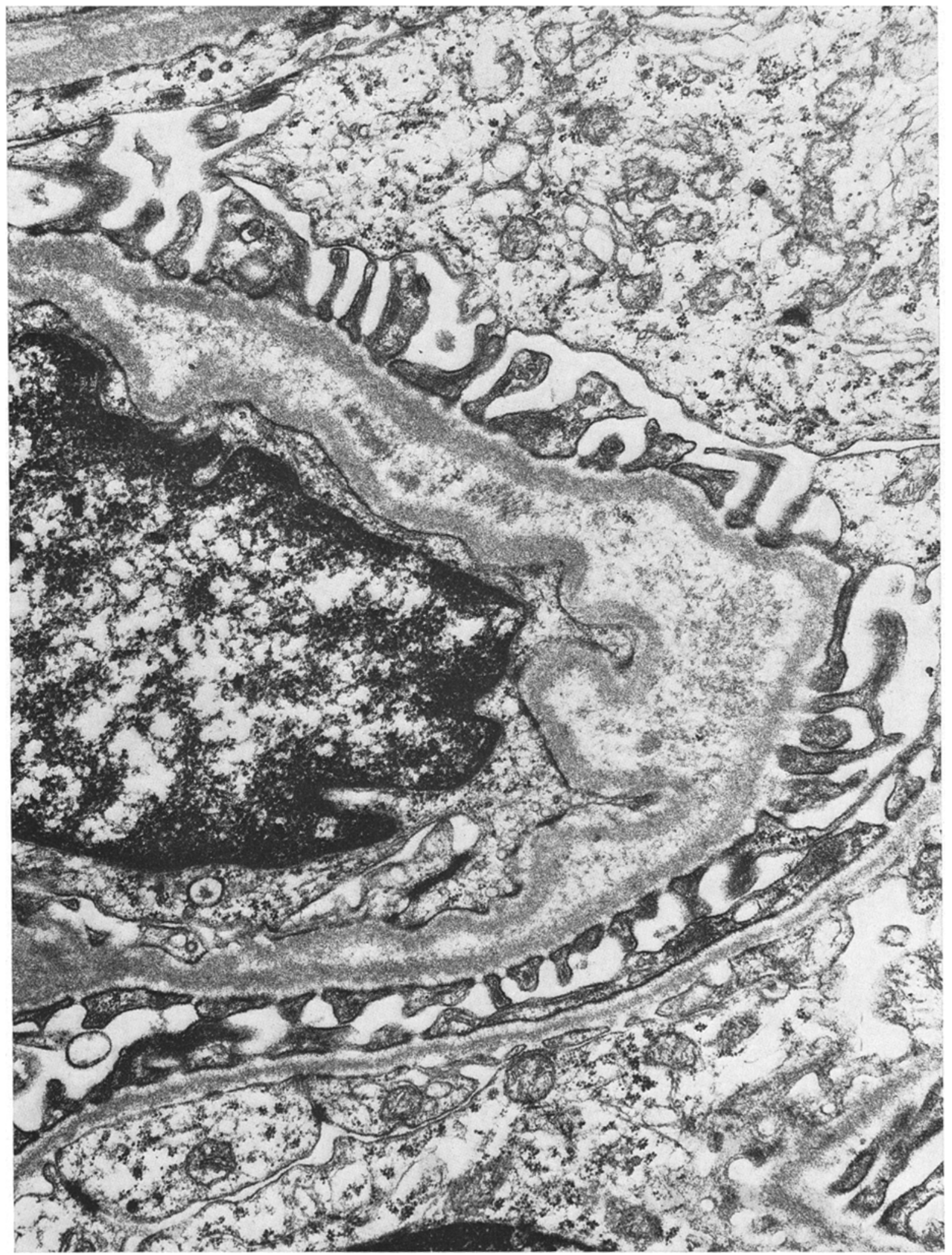

Fig. 5. Splitting of the glomerular basement membran. Rabbit, treated for 1 month with $a$ and $b$ component. $49400: 1$ 


\section{Insulin-Binding Capacity}

The findings in Table 2 show that $\mathrm{a}+\mathrm{b}$ component leads to the production of significantly higher antibody titers as compared with MC insulin and the solvent.

\section{Correlation between Basement Membrane Changes and Antibody Titers}

If one compares the antibody titers and the prevalence of the subepithelial basement membrane protuberances during the period of the study it is evident that there is a certain correlation between these two parameters in the animals which had been treated with $a+b$ component. In the $a+b$-group we find significant higher antibody-titers and significant increased subepithelial basement membrane protuberances contrary to the norm and to the MC-group. In the MC-group, however, there is no increase of the antibody-formation compared with the solvent-group
2. On prolonged immunization of rabbits with $\mathrm{MC}$ insulin there is no increased occurrence of subepithelial basement membrane protuberances as compared with untreated control animals and solvent-treated animals.

3. There is a significantly higher antibody titer in the animals which had been treated with $a+b$ component.

4. A marked increase in the subepithelial basement membrane protuberances is to be observed in the animals treated with $a+b$ component.

5. During the course of immunization particularly with $\mathrm{a}+\mathrm{b}$ component exists a direct relationship between the IBC of the serum and the prevalence of the subepithelial basement membrane protuberances.

6. Subepithelial basement membrane protuberances varely occur in normal rabbits and sporadically in the solvent group.

Table 1. The prevalence of subepithelial basement membrane protuberances in per cent of glomeruli studied (Means $\pm S . D).(n=$ the number of animals, 100 glomeruli of each animal were evaluated, in the $a+b-$ solvent group -50 glomeruli)

\begin{tabular}{lrrrlrr}
\hline & \multicolumn{1}{c}{ 4 weeks } & \multicolumn{1}{c}{$\mathrm{n}$} & \multicolumn{1}{c}{8 weeks } & $\mathrm{n}$ & 12 weeks & $\mathrm{n}$ \\
\hline MC-Insulin & $2.2 \pm 0.8$ & 10 & $5.3 \pm 2.1$ & 10 & $\mathbf{1 . 9} \pm 1.2$ & 10 \\
MC-Solvent & 0.0 & 5 & $6.4 \pm 1.9$ & 10 & $4.7 \pm 2.5$ & 5 \\
a + b-Component & $39.9 \pm 8.5$ & 10 & $27.2 \pm 6.3$ & 10 & $14.1 \pm 5.0$ & 6 \\
a +b-Solvent & $12.8 \pm 6.3$ & 5 & & & $5.2 \pm 1.9$ & 5 \\
Normal & & & $1.1 \pm 1.0$ & $(\mathrm{n}=50)$ & \\
\hline
\end{tabular}

Table 2. Behaviour of the insulin-binding capacity of the serum of rabbits ( $\mu$ insulin/ml serum) which had been treated with different insulin preparations over various periods of time (means $\pm S . D).(\mathrm{n}=$ number of animals studied)

\begin{tabular}{|c|c|c|c|c|c|c|c|c|}
\hline $\begin{array}{l}\text { Duration } \\
\text { (weeks) }\end{array}$ & $\mathrm{n}$ & MC-Insulin & $\mathrm{n}$ & $a+b$-Component & $\mathrm{n}$ & MC-Solvent & $\mathrm{n}$ & $a+b$-Solvent \\
\hline 2 & & & 10 & $0.57+0.03$ & & & & \\
\hline 4 & 10 & $0.17 \pm 0.03$ & 10 & $0.73 \pm 0.09$ & 10 & $0.18 \pm 0.04$ & 5 & $0.12 \pm 0.01$ \\
\hline 6 & 10 & $0.15 \pm 0.03$ & 6 & $0.42 \pm 0.01$ & & & & \\
\hline 8 & 10 & $0.17 \pm 0.04$ & 10 & $0.35 \pm 0.02$ & 10 & $0.17 \pm 0.01$ & 5 & $0.17 \pm 0.01$ \\
\hline 12 & 10 & $0.27 \pm 0.02$ & 6 & $0.33 \pm 0.02$ & 5 & $0.12 \pm 0.02$ & 5 & $0.12 \pm 0.01$ \\
\hline 18 & 2 & $0.20 \pm 0.05$ & 2 & $0.40 \pm 0.01$ & & & & \\
\hline 24 & & & 2 & $0.50 \pm 0.01$ & & & & \\
\hline 28 & 2 & $0.13 \pm 0.03$ & 2 & $0.44 \pm 0.02$ & & & & \\
\hline 32 & 1 & 0.29 & & & & & & \\
\hline 40 & 2 & $0.25 \pm 0.04$ & & & & & & \\
\hline
\end{tabular}

and the prevalence of the subepithelial basement membrane protuberances, too, is statistically not increased compared with the norm. Subsequently higher antibody-titers are accompanied by an increase in formation of subepithelial basement membrane protuberances (Table 1 and 2 ).

\section{Discussion}

On summarizing the findings one can draw the following conclusions:

1. No significant antibody formation is demonstrable in the rabbits treated with MC insulin.
Hence, the findings are consistent with the results of other investigators who found no or only extremely slight antibody formation in rabbits (Schlichtkrull, $1970,1971 \mathrm{a}, \mathrm{b}$ ) and in human diabetics (Wegmüller and Fankhauser, 1970; Fankhauser and Michl, 1971) following treatment with MC insulin. However of course antibody formation depends not only on the purity of the insulin preparation but also on the duration of immunization (Jansen, 1971) and the $\mathrm{pH}$ of the solution. For instance, Deckert and Grundahl (1970) employing crystalline porcine insulin in neutral solution in high dosage could not demonstrate any antibody formation in diabetics. On the other hand one must bear in mind that porcine insulin has a less 
marked immunogenic effect than bovine insulin (Schlichtkrull, 1970). In contrast, if one treats rabbits with $\mathrm{a}+\mathrm{b}$ component, hence with the impurities removed from eommercial insulin preparations, then one can observe significantly higher and unequivocally demonstrable antibody formation. This is consistent with the studies of Schlichtkrull (1970) who achieved similar results employing a similar assay system. Likewise Fankhauser (1969) emphasizes that regular insulin of a low degree of purity regularly leads to the production of antibodies. The findings clearly illustrate that the impurities present in the insulins in normal commercial usage at the present time are alone responsible for the greater antigenicity. It has not as yet been clarified as to which of the various impurities are responsible. According to Hinke and associates (1970) it does not appear to be proinsulin although it is postulated that no significant differences exist between insulin and proinsulin as far as their immunogenicity is concerned (Kerp and associates, 1970). However the individual components of proinsulin evidently show a different behaviour. For instance, the B-chain component is regarded as being immunologically inactive whereas it is claimed that immunologically the A-chain component is not insulin-like (Surmaczynska and Metz, 1969) and that the C-peptide possesses the most potent antigenic determinants (Rubenstein and associates, 1969). In any case when performing all such studies one must bear in mind that the behaviour of insulin, proinsulin and their derivatives depends to a great extent on the immunological system in which it is studied (Wright and Makuli, 1970).

The results which we achieved on immunization with MC insulin point out a new direction for insulin therapy following which the occurrence of insulin antibodies and the possibly resulting insulin resistance could be well-nigh avoided. This is of potentially great importance since the avoidance and treatment of this form of insulin resistance remains a virtually unsolved problem.

In a previous study of the glomeruli of insulinimmunized guinea pigs we assumed that the glomerular basement membrane changes, namely the so-called "humps", were depositions of antigen-antibody complexes (Wehner and associates, 1969). Based on our electron microscopic findings reported in this paper these are basement membrane protuberances of the same electron density as the lamina densa without any basal demarcation of these nodules by a lamina rara externa. According to Kimmelstiel and associates (1967) the latter form of "humps", which can occur in five variations, are actual immune complex depositions. The significance of such a differentiation of the shape of the humps and of diagnostic aspects has remained controversial and has been disputed (Churg, 1967). In spite of the variation in structure of the humps we would like to assume that at least part of them are immune complex depositions as similar changes which were verified by electron microscopy have been demonstrated in large number in an inbred strain of mice with spontaneous immune complex nephritis (van Noord and associates, 1972). In this connection the report of Orci and associates (1970) is of interest, they demonstrated identical basement membrane protuberances in diabetic spiny mice, it may be relevant that these animals are said to posses two different insulins (Balant and associates, 1971). On the other hand as yet we have only been able to show that these structures occur more frequently on immunization with insulin preparations possessing a more potent antigenic action and that increased and atypical synthesis of basement membrane material occurs. Based on their findings Like and associates (1972) likewise observed very characteristic subepithelial basement membrane nodules in diabetic mouse mutants whose aetiology is thus far unclarified.

Thus the actual cause of the increase in the prevalence of the subepithelial basement membrane protuberances with increasing antigenicity of the insulin preparation still remain unclarified. A new surprising fact was the occurence of subepithelial basement membrane protuberances in normal animals and in the solvent-group. We cannot explain this fact; perhaps it is caused by impurities or infective toxins, because we know that in rodents spontaneous glomerular alterations may occur with increasing age of animals.

Acknowledgements. We are indebted to Dr. Schlichtkrull (Novo-Research Institute, Copenhagen, Denmark) for supplying the insulin preparations. We wish to thank Professor Dr. E. Kallee, Division of nuclear Medicine, Department of Medicine, University of Tübingen, for allowing us to carry out part of the experiments in his laboratories.

\section{References}

Balant, L., Burr, I.M., Stauffacher, W., Cameron, D.P., Buenzli, H.F., Humbel, R.E., Renold, A.E.: Insulin of spiny mice (Acomys cahininus) - Partial characterization and evidence for two insulins. Endocrinology 88, $517-521$ (1971).

Churg, J., discussion to Jennings, R.: Pathology and natural history of acute glomerulonephritis. In: Acute Glomerulonephritis, p. 101-129. Ed.: Metcoff, J. Boston: Little Brown and Comp. 1967.

Deckert, T., Grundahl, E.: The antigenicity of pig insulin. Diabetologia 6, 15-20 (1970).

Fankhauser, S.: Neuere Aspekte der Insulintherapie. Schweiz. med. Wschr. 99, 414-420 (1969).

Fankhauser, S., Michl, J.: New possibilities to avoid the formation of insulin - antibodies in diabetic patients. Abstracts: European Ass. for Study of Diabetes, 7th Ann. Meeting, Southampton 1971.

Hinke, H., Steinhilber, S., Kasemir, H., Kerp, L.: Quantitative Untersuchungen zur Antikörperbindung von Rinderinsulin und Rinderproinsulin im Serum insulinbehandelter Diabetiker. Verh. dtsch. Ges. inn. Med. 76, $375-378$ (1970).

Jansen, F.K.: Monocomponent insulin and $1 \times$ crystallized insulin in the development of immunological tolerance in mice. Abstracts: European Ass. for Study of Diabetes, 7th Ann. Meeting, Southampton 1971. 
Kallee, E., Debiasi, S., D'Addabbo, A.: Studies on $131 \mathrm{~J}$ labelled insulin. VI. Immunological experiments on the binding of 131-I-insulin to serum proteins of normal, analbuminemic, and insulin-treated subjects. Acta isotop. 3,239 (1963).

Kerp, L., Steinhilber, S., Kasemir, H.: Besitzt die Proinsulinverunreinigung kommerzieller Insulinpräparate Bedeutung für die Stimulierung von Insulinantikörpern? Klin. Wschr. 48, 884-885 (1970).

Kimmelstiel, P., Osawa, G., Beres, J.: Some glomerular changes by electron microscopy with predominant mesangial reaction. Proe. $3 \mathrm{rd}$ int. Congr. Nephrol., Vol. 2, 17-32. Basel u. New York: Karger 1967.

Like, A. A., Lavine, R., Poffenbarger, P. L., Chick, W.L.: Studies in the diabotic mutant mouse. VI. Evolution of glomerular lesions and associated proteinuria. Amer. J. Path. 66, 193-224 (1972).

Noord, van M.J., Pelt, van F.G., Hollander, C.F. Daems, W.T.: The development of ultrastructural glomerular alterations in Praomys (Mastomys) natal. ensis. An electron microscopic study. Lab. Invest. 26, $364-375$ (1972).

Orci, L., Stauffacher, W., Amherdt, M., Pictet, R. Renold, E., Rouiller, Ch.: The kidney of spiny mice (Acomys cahirinus): Electron microscopy of glomerular changes associated with ageing and tubular glycogen accumulation during hyperglycemia. Diabetologia $6,343-355(1970)$.

Rubenstein, A.H., Steiner, D.F., Cho, S.: Immunological properties of bovine proinsulin and related fractions. Diabetes 18, 598-605 (1969).

Sabatini, D.D., Bensch, K.G., Barrnett, R.J.: Preservation of ultrastructure and enzymatic activity of aldehyde fixation. J. Histochem. Cytochem. 10, 652$653(1962)$.
Schlichtkrull, J.: Proinsulin und verwandte Proteine chemische und biologische Untersuchungen. Verh. dtsch. Ges. inn. Med. 76, 14-21, 1970.

Schlichtkrull, J.: Proinsuline et substance apparentées. Path. et. Biol. 19, 885-892, 1971 a.

Schlichtkrull, J.: Monocomponent insulin. Abstracts: European Ass. for Study of Diabetes, 7th Ann. Meeting, Southampton $1971 \mathrm{~b}$.

Surmaczynska, B., Metz, R.: Hormonal and immunological properties of insulin fragments: I. The individual peptide chains. Endocrinology 85, 368-372 (1969).

Wegmüller, E., Fankhauser, S.: Die Antigenität verschiedener Depotinsulinpräparate bei Diabetikern. Helv. med. Acta, Suppl. 50, 130 (1970).

Wehner, H., Schade, U., Asante, F.: Veränderungen an der glomerulären Basalmembran des Meerschweinchens durch Fremdinsulin und ihre Beziehung zur Höhe der Insulin-Bindungsfähigkeit des Serums. Virchows Arch. path. Anat. Abt. A 348, 164-169 (1969).

Wehner, H.: Morphologische Methoden in der Routinediagnostik der Nierenpathologie (Glomerulonephritis). Beitr. Path. 141, 402-403, 1970.

Wehner, H., Faix-Schade, U., Wehner, I., Veigel, J.: Insulin-antibodies and azathioprine (Imurel). Horm. Metab. Res. 4, 62-64, 1972.

Wright, P.F., Makuli, D.R.: Reactions of proinsulin and its derivatives with antibodies to insulin. Proc. Soc. exp. Biol. 134, 1165 1169 (1970).

Priv.-Doz. Dr. H. Wehner

Path. Institut d. Universität

D-7400 Tübingen

Liebermeisterstr. 8

Federal Republic of Germany 